\title{
Study on Relationship between Dielectric Constant and Water Content of Rock-Soil Mixture by Time Domain Reflectometry
}

\author{
Daosheng Ling, ${ }^{1,2}$ Yun Zhao,, ${ }^{1,2}$ Yunlong Wang, ${ }^{1,2}$ and Bo Huang ${ }^{1,2}$ \\ ${ }^{1}$ MOE Key Laboratory of Soft Soils and Geoenvironmental Engineering, Zhejiang University, Hangzhou 310058, China \\ ${ }^{2}$ Institute of Geotechnical Engineering, Zhejiang University, Hangzhou 310058, China \\ Correspondence should be addressed to Bo Huang; cehuangbo@zju.edu.cn
}

Received 24 January 2016; Accepted 20 March 2016

Academic Editor: Fei Dai

Copyright (c) 2016 Daosheng Ling et al. This is an open access article distributed under the Creative Commons Attribution License, which permits unrestricted use, distribution, and reproduction in any medium, provided the original work is properly cited.

\begin{abstract}
It is important to test water content of rock-soil mixtures efficiently and accurately to ensure both the quality control of compaction and assessment of the geotechnical engineering properties. To overcome time and energy wastage and probe insertion problems when using the traditional calibration method, a TDR coaxial test tube calibration arrangement using an upward infiltration method was designed. This arrangement was then used to study the influence of dry density, pore fluid conductivity, and soil/rock ratio on the relationship between water content and the dielectric constant of rock-soil mixtures. The results show that the empirical calibration equation forms for rock-soil mixtures can be the same as for soil materials. The effect of dry density on the calibration equation has the most significance and the influence of pore fluid conductivity can be ignored. The impact of variation of the soil/rock ratio can be neutralized by considering the effect of dry density in the calibration equation for the same kind of soil and rock. The empirical equations proposed by Zhao et al. show a good accuracy for rock-soil mixtures, indicating that the TDR method can be used to test gravimetric water content conveniently and efficiently without calibration in the field.
\end{abstract}

\section{Introduction}

Rock-soil mixtures are widely used in engineering projects such as roads, dams, and foundations. It is of great importance to efficiently and accurately test water content for the control of compaction quality and the assessment of engineering properties in geotechnical engineering. As the dielectric constant value for water (around 81 at $20^{\circ} \mathrm{C}$ ) is much larger than for solids (around 3 5), the time domain reflectometry (TDR) method uses the relationship between water content and electromagnetic parameters of geomaterials to obtain water content. TDR has the advantages of speed, reliability, and the availability of automatic monitoring.

Researchers have established many models relating electromagnetic parameters and soil water content, including the polynomial empirical equation, the linear model relating volumetric water content to dielectric constant, and the equations relating electromagnetic parameters to gravimetric water content and dry density [1-10]. The experimental data sources of the equations, however, come mainly from soil material and municipal solid waste (MSW). There is little material in the literature concerning rock-soil mixtures. Compared with soil and MSW materials, rock-soil mixtures differ greatly in, for example, the ranges of particle size, dry density, composition, and uniformity. The differences in dielectric response under the electromagnetic waves, between rock-soil mixture and soil, and the possibility of using TDR technology to test the water content of rock-soil mixtures are still at the exploratory stage [11-13]. The limited amount of past research mainly concerns the calibration of a specific rock-soil mixture and is not yet related to the study of the complex environments encountered in geotechnical engineering such as variations in soil/rock ratios, dry density, and the pore fluid conductivity.

Based on the upward infiltration method, proposed in this paper, a TDR calibration apparatus suitable for compacted geomaterials when combined with an infiltration device is built onto the TDR coaxial test tube. Three typical soils commonly used in engineering were first examined to test the ability of this apparatus. The dielectric properties of 
an artificially prepared rock-soil mixture and the influence of dry density, pore fluid conductivity, and the soil/rock ratio on the relationship between water content and dielectric constant were then studied. Considering the calibration difficulty in the field, some empirical equations were given to conveniently and efficiently test water content in the field by the TDR method without calibration.

\section{Test Apparatus and Experimental Verification}

2.1. Upward Infiltration Method. To calibrate the relationship between water content and dielectric constant, the traditional method usually involves a group of samples with stepwise increasing water content. After TDR test and the analysis of collected waveforms, calibration curve is obtained by regression analysis. One point corresponds to one sample and since many data points are needed for effective rock-soil mixture research, the traditional method takes much time and energy; hence, a more efficient method is required.

Existing experimental results $[14,15]$ show that the water content obtained by TDR for a soil sample is the average value of water content along the length of the TDR probe. The actual distribution of water content in the sample has almost no influence on the result. The "upward infiltration method" of calibration, which utilizes an infiltration device at the bottom of the apparatus to add water to the soil sample and thus obtains a series of water content and dielectric constant data points, appears to be a natural improvement. The literature [16] has theoretically demonstrated why the upward infiltration method could be used in association with the square root model. In the study, [17] calibration tests using this method were conducted for typical soils encountered in agriculture. The results showed that the method provided a good accuracy and reliability. Compared with traditional method, the upward infiltration method is efficient and is utilized extensively in agriculture and environmental geotechnics [18-20]. The existing apparatus used for the upward infiltration method usually consists of two- or threerod TDR probe, PVC material forming the outer cylinder, and the corresponding infiltration device and is suitable for loose soil samples with low density. For geotechnical engineering, however, in particular for compacted rock-soil mixture samples, application of this method is limited as it is difficult to insert the TDR probe.

2.2. Test Setup. The upward infiltration TDR coaxial test tube systems mainly include the TDR test and infiltration device as shown in Figure 1(a). The TDR coaxial test tube specified in ASTM D6780-12 [21] was utilized in this study, as the TDR test component. The center probe and the tube, respectively, simulate the inner and outer conductor of the coaxial cable. When combined with a guiding template, this arrangement can effectively solve the probe insertion problem. Meanwhile, a controllable infiltration device is added to the bottom of the tube. This device is composed of, for example, a Mariotte bottle, water pipe, sealing clip, infiltration base, porous stone, washer, and rubber ring as shown in Figure 1(b). The flow infiltrates uniformly upwards into the sample through the porous stone under the constant head. The sealed washer acts to avoid spilled water. The TDR coaxial test tube has a height of $17 \mathrm{~cm}$ and an inside diameter of $10 \mathrm{~cm}$. It is connected to the infiltration base by a fixing plate and its built-in rubber ring with bolts.

The TDR tests were conducted using the Campbell Scientific TDR100 apparatus and its associated PCTDR software. For example, the coaxial head, guiding template, and probe device, used in the study, were as recommended by ASTM D6780-12. The TDR waveforms were analyzed as described in the study [22] to obtain the dielectric constant values.

\subsection{Experimental Verification of the Setup}

2.3.1. Test Scheme. The three typical soils Fujian sand, Qiantang silt, and Hangzhou clay, commonly encountered in geotechnical engineering, were tested using the upward infiltration method and traditional calibration method. The properties of these soils including the specific gravity of solids (Gs), liquid limit (LL), plasticity index (PI), and grainsize distributions and their types according to the Unified Soil Classification System (USCS) are shown in Table 1. For simplicity, the soils are referred to, below, as FJS, QTS, and HZC, respectively.

In the upward infiltration method tests, the soil sample, with an initial uniform distribution of water content, was compacted in layers, within the coaxial tube to a specific dry density. Water then uniformly infiltrated upwards into the soil sample through the porous stone due to the constant head provided by the Mariotte bottle. The sealing clip was closed when the water content of the sample reached a targeted value. The water content was obtained by measuring the change in weight with an electronic balance, having a maximum weighting range of $15 \mathrm{~kg}$ and a maximum allowable error $\pm 5 \mathrm{~g}$, while the dielectric constant value for the sample was obtained by the TDR test. Thus, a series of sample data points including water content and dielectric constant with a specific dry density could be obtained. Three samples were prepared for each soil, of which samples $1 \#$ and 2\# were used to study the influence of dry density on the calibration while samples $2 \#$ and $3 \#$ were tested to study the effects of initial water content. In total, 9 groups of upward infiltration experiments were conducted, as shown in Table 2.

The traditional calibration method was performed to compare the results with those of the upward infiltration method. After oven drying and sieving, the soil samples were mixed with tap water to the targeted water contents. The soil samples were then packed into a sealed plastic bag and placed in a room at constant temperature around $20^{\circ} \mathrm{C}$ for 24 hours. Later, the samples were compacted in the mould according to ASTM D698-12 [23] and a TDR test was then conducted. Finally, the soil samples were oven dried to obtain the actual gravimetric water content. Six to seven samples were prepared for each type of soil. The gravimetric water content range included $0.03 \sim 0.18 \mathrm{~g} / \mathrm{g}, 0.06 \sim 0.24 \mathrm{~g} / \mathrm{g}$, and $0.06 \sim 0.19 \mathrm{~g} / \mathrm{g}$ for FJS, QTS, and HZC, respectively. Correspondingly, their respective dry densities varied within $1.51 \sim 1.57 \mathrm{~g} / \mathrm{cm}^{3}, 1.52 \sim 1.65 \mathrm{~g} / \mathrm{cm}^{3}$, and $1.32 \sim 1.59 \mathrm{~g} / \mathrm{cm}^{3}$. 
TABLE 1: Physical properties of soils.

\begin{tabular}{lccccccc}
\hline Soil & USCS & Gs & LL & PI & Sand $(>0.075 \mathrm{~mm}) / \%$ & Silt $(0.005 \sim 0.075 \mathrm{~mm}) / \%$ & Clay $(<0.005 \mathrm{~mm}) / \%$ \\
\hline FJS & SP & 2.64 & ND & ND & 100 & 0 & 0 \\
QTS & ML & 2.69 & 31.7 & 9.1 & 11.2 & 83 & 5.8 \\
HZC & CL & 2.66 & 48 & 15.4 & 11.4 & 51.9 & 36.7 \\
\hline
\end{tabular}
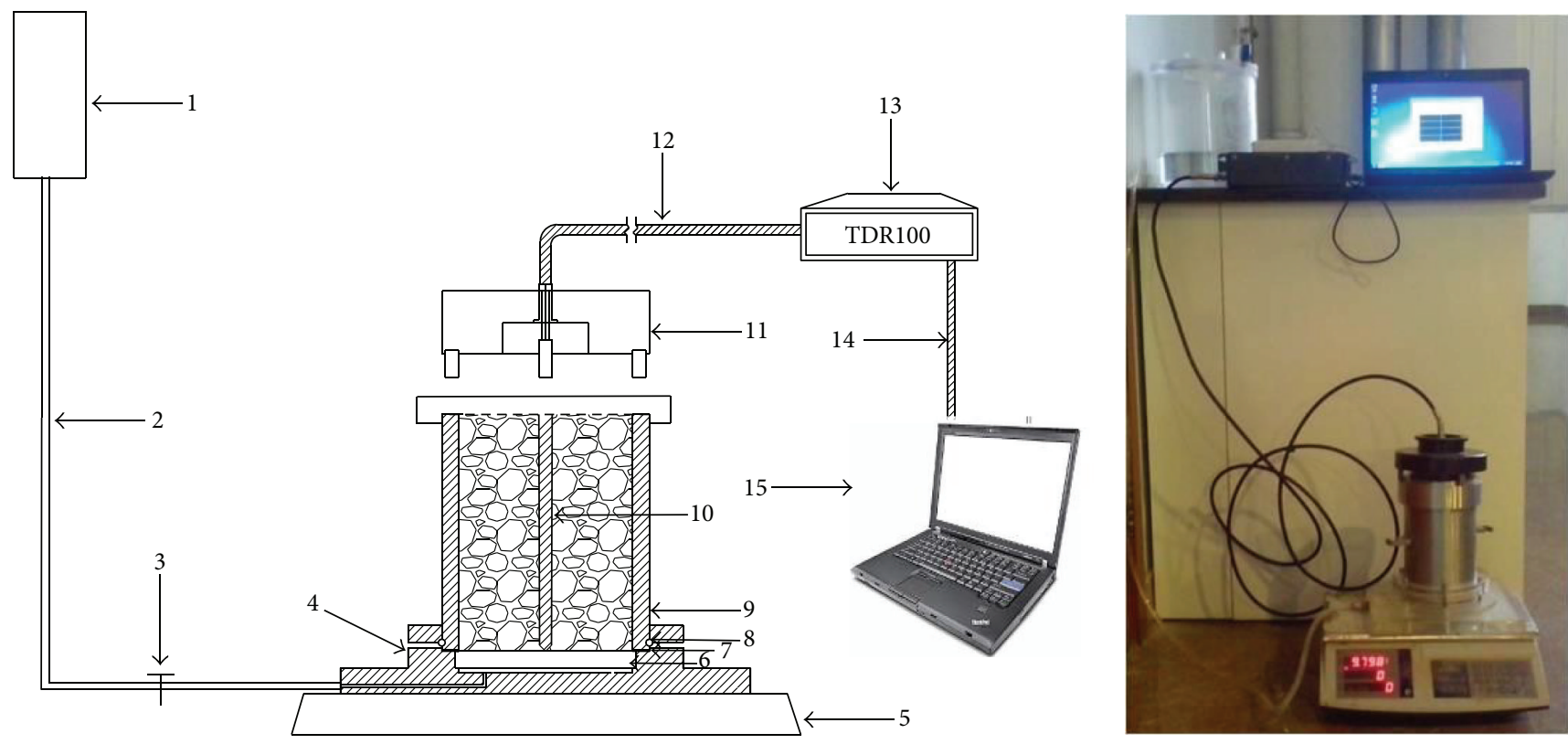

(a) Upward infiltration method apparatus
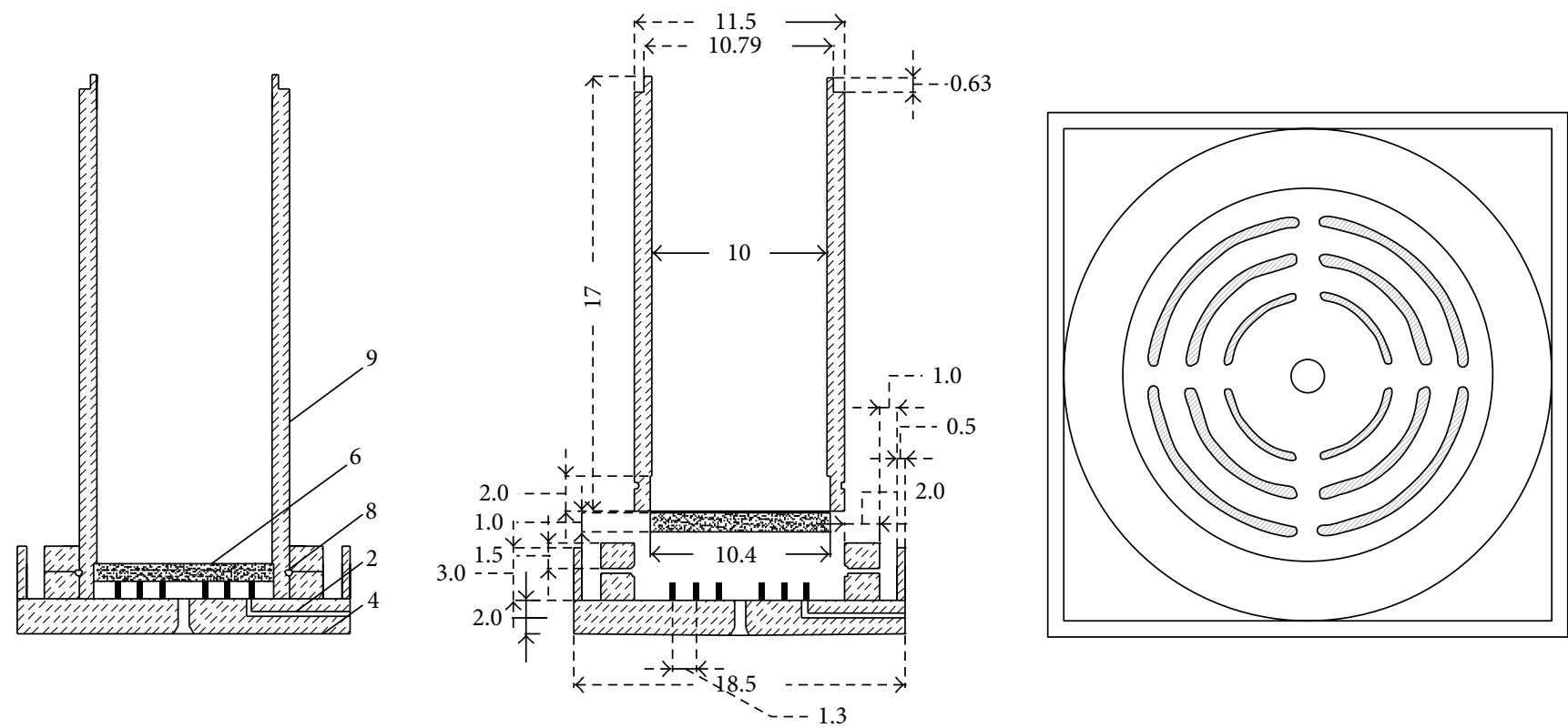

(b) TDR coaxial test tube and infiltration device

FIGURE 1: The upward infiltration TDR coaxial test tube systems. 1, Mariotte bottle, 2, water pipe, 3, sealing clip, 4, infiltration base, 5, electrical balance, 6 , porous stone, 7 , washer, 8 , rubber ring, 9 , coaxial test tube, 10, center rod, 11, coaxial head, 12, coaxial cable, 13, TDR100 pulse generator, 14, data cable, and 15, computer. 
TABLE 2: Conditions for upward infiltration experiments.

\begin{tabular}{|c|c|c|c|}
\hline Soil & Group & Initial water content/g.g ${ }^{-1}$ & Dry density/g. $\mathrm{cm}^{-3}$ \\
\hline \multirow{3}{*}{ FJS } & $1 \#$ & 0.029 & 1.24 \\
\hline & $2 \#$ & 0.028 & 1.49 \\
\hline & $3 \#$ & 0.055 & 1.50 \\
\hline \multirow{3}{*}{ QTS } & $1 \#$ & 0.027 & 1.41 \\
\hline & $2 \#$ & 0.023 & 1.54 \\
\hline & 3\# & 0.044 & 1.57 \\
\hline \multirow{3}{*}{ HZC } & $1 \#$ & 0.025 & 1.10 \\
\hline & $2 \#$ & 0.027 & 1.26 \\
\hline & $3 \#$ & 0.054 & 1.27 \\
\hline
\end{tabular}

2.3.2. Soil Test Result. In geotechnical engineering, the gravimetric water content is used more extensively [23]. At present, the most widely used empirical models relating gravimetric water content and dielectric constant are the Purdue model (1) and the empirical equation proposed by Zhao et al. (2) and its modified form taking account of the effect of dry density (3):

$$
\begin{aligned}
\frac{\sqrt{K_{a}}}{\rho_{d}} & =a_{1}+b_{1} w, \\
w & =\frac{\left(a_{2}+\sqrt{K_{a}}\right)}{\left(b_{2}+c_{2} \sqrt{K_{a}}\right)}, \\
w & =\frac{\left(a_{3} \rho_{d} / \rho_{w}+b_{3}\right)+\sqrt{K_{a}}}{\left(c_{3} \rho_{d} / \rho_{w}+d_{3}\right)+\left(f_{3} \rho_{d} / \rho_{w}+g_{3}\right) \sqrt{K_{a}}},
\end{aligned}
$$

where $K_{a}$ is the dielectric constant, $\rho_{d}$ is the dry density, $w$ is the gravimetric water content, $\rho_{w}$ is the density of water, and $a_{1}, b_{1}, a_{2}, b_{2}, c_{2}, a_{3}, b_{3}, c_{3}, d_{3}, f_{3}$, and $g_{3}$ are calibration constants.

In order to quantify and evaluate the calculated water content results produced by each equation, statistical quantitative evaluation indexes were adopted and are defined as follows:

(1) Errors $(\Delta w)$ : reflecting the differences between water contents calculated by (1) (3) and the directly measured values:

$$
\Delta w=w-w_{o}
$$

where $w_{o}$ is the directly measured value of gravimetric water content.

(2) Average errors $(E)$ : reflecting the average errors calculated by $(1) \sim(3)$ :

$$
E(\Delta w)=\frac{\sum_{1}^{n}|\Delta w|}{n},
$$

where $n$ is the number of data points.

(3) Standard errors of estimate (SEE): estimating the dispersion of the overall errors:

$$
\mathrm{SEE}=\sqrt{\frac{\sum_{1}^{n}(\Delta w)^{2}}{(n-2)}} .
$$

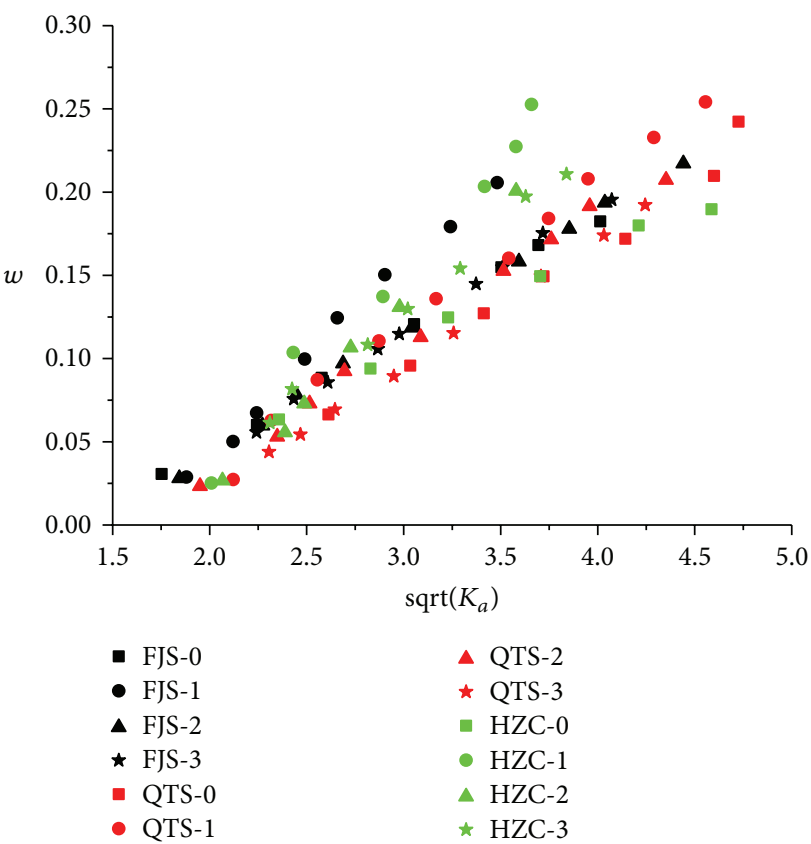

FIGURE 2: Relationship between gravimetric water content and square root of dielectric constant.

Figure 2 demonstrates the relationship between gravimetric water content and the square root of the dielectric constant and Figure 3 shows the result of the Purdue model, where group 0 represents the result obtained by the traditional calibration method. As shown in Figure 2, for FJS and QTS soils, the distributions of data points obtained by the upward infiltration method and the traditional calibration method show good consistency, indicating that the upward infiltration method can give a good calibration result. For HZC soil, however, the result is not satisfactory. The difference can be attributed to the relatively large difference in dry density between the samples of the upward infiltration method and the traditional calibration method. When the form of (1) is adopted, as shown in Figure 3, the two methods give consistent results for all three types of soil.

Table 3 presents the calibration results of (2) and the statistical calculated water content results produced by the calibration equation for all data points for soils of the same type. As shown in Table 3, the experimental data points in each group have a high value of correlation coefficient $R^{2}$ with the fitted function. The values of $E$ and SEE for each group are at a low level, suggesting that the upward infiltration method and traditional calibration method can give a similar result. It should be pointed out that the statistical result for group 1 of the HZC soil is obviously larger. The reason is that (2) is nonlinear and the effect of dry density is not taken into account. This caused the calibration function inflection point to advance leading to large errors at those data points with higher water content or a high dry density. The statistical results for soil groups of the same type by upward infiltration method are similar, indicating that the calibration results are not sensitive to the influence of initial water content and dry density at these tests. 
TABLE 3: Results of fitting (2).

\begin{tabular}{lcccccc}
\hline \multirow{2}{*}{ Group } & \multicolumn{6}{c}{$w=\left(a_{2}+\sqrt{K_{a}}\right) /\left(b_{2}+c_{2} \sqrt{K_{a}}\right)$} \\
& $a_{2}$ & $b_{2}$ & $c_{2}$ & $R^{2}$ & $E$ & SEE \\
\hline FJS-0 & -1.3745 & 12.7163 & 0.3655 & 0.9959 & 0.0087 & 0.0165 \\
FJS-1 & -1.7022 & 5.8020 & 0.8172 & 0.9948 & 0.0313 & 0.04045 \\
FJS-2 & -1.5023 & 11.1552 & 0.5262 & 0.9985 & 0.0078 & 0.0162 \\
FJS-3 & -1.5604 & 10.9765 & 0.4351 & 0.9974 & 0.0087 & 0.0166 \\
QTS-0 & -1.3323 & 23.3387 & -1.8429 & 0.9796 & 0.0148 & 0.0201 \\
QTS-1 & -1.7620 & 8.6556 & 0.5237 & 0.9923 & 0.0173 & 0.0228 \\
QTS-2 & -1.7231 & 9.0120 & 0.7806 & 0.9935 & 0.0123 & 0.0148 \\
QTS-3 & -1.6963 & 14.8962 & -0.3802 & 0.9996 & 0.0129 & 0.0184 \\
HZC-0 & -1.6742 & 6.6580 & 1.8465 & 0.9944 & 0.0259 & 0.0399 \\
HZC-1 & -1.7585 & 7.5230 & 0.0938 & 0.9723 & 0.0365 & 0.0559 \\
HZC-2 & -1.8615 & 8.4297 & 0.0295 & 0.9937 & 0.0237 & 0.0403 \\
HZC-3 & -1.5098 & 14.2777 & -0.8820 & 0.9909 & 0.0229 & 0.0362 \\
\hline
\end{tabular}

Because of the limit imposed on the length of this paper, only (2) analysis result is given. Other calibration equations gave a similar result. As discussed above, the upward infiltration method can give accurate calibration results. The initial water content and the dry density of the calibration sample will influence the values of the calibration constants but have no obvious effect on the calculated water content. The apparatus used in this study proved to be highly stable and can be efficiently used to calibrate the relationship between the water content and dielectric constant.

\section{Dielectric Properties Tests of Rock-Soil Mixture}

3.1. Test Materials. To study the relationship between the water content and dielectric constant of rock-soil mixtures, rock material was taken from a building materials site for this experiment. A diameter of $1 \sim 2 \mathrm{~cm}$ was classified as fine gravel by ASTM D2487-11 [24]. The soil material adopted is classified as CL soil by USCS and was dug from a foundation pit excavation in the locality. The specific gravity of this soil was 2.76 and the respective liquid limit and plasticity index were $48 \%$ and $22.6 \%$. The respective silt fraction $(0.075 \sim$ $0.005 \mathrm{~mm})$ and clay fraction $(<0.005 \mathrm{~mm})$ percentages were $47.3 \%$ and $44.7 \%$. Photographs of the rock and soil material are shown in Figure 4.

3.2. Test Scheme. Since rock-soil mixtures in practical engineering usually possess various levels of compactness and pore fluid conductivities, it was necessary to study the effect of these factors on the calculated water content values. Samples $1 \# \sim 5 \#$ were studied to ascertain the influence of dry density and pore fluid conductivity. The test samples were prepared by mixing the soil and rock material in the quantity ratio of $5: 5$. Calibration samples with different dry densities were obtained by changing the compaction energy levels and the test samples with different pore fluid conductivities were prepared by utilizing various concentrations of $\mathrm{KCl}$ solution as the pore fluid. In addition, as it is difficult to control the ratio of soil and rock in the field test or in compaction

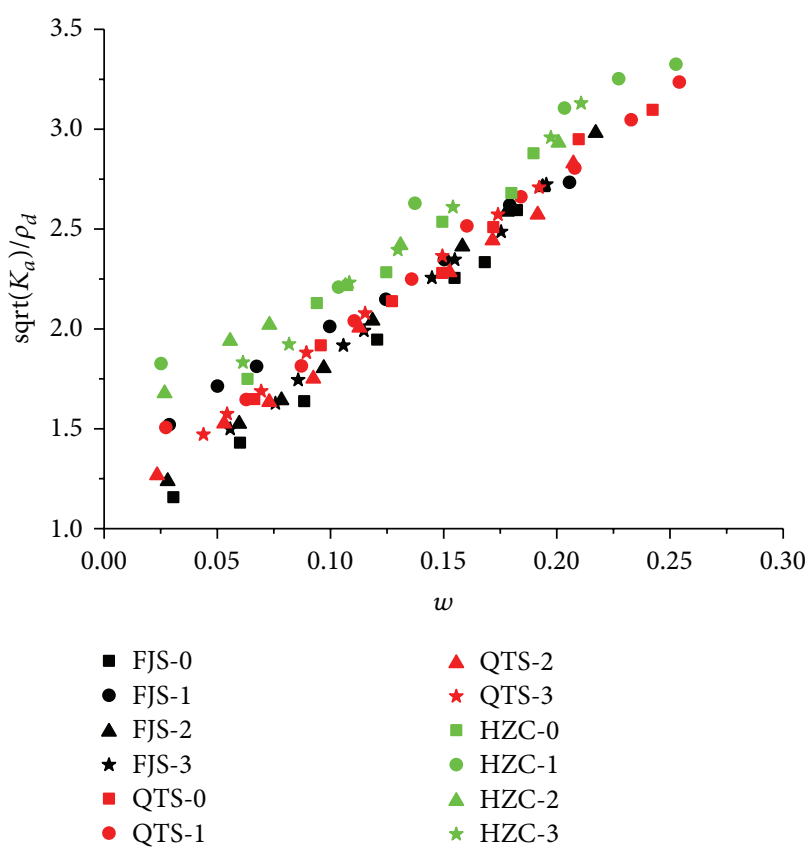

FIgURE 3: Relationship of Purdue equation.
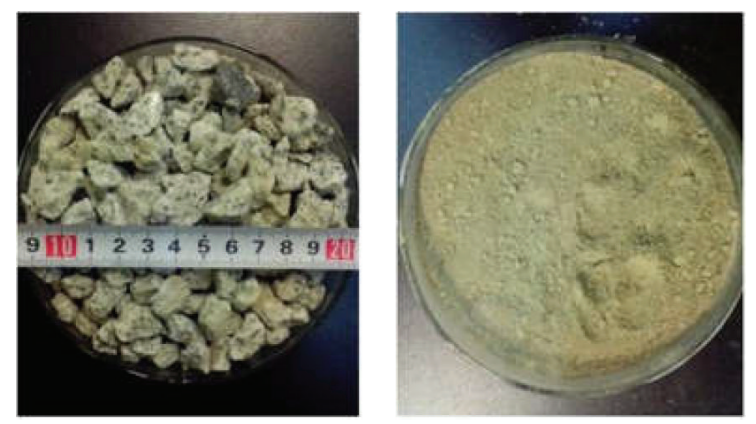

FIGURE 4: Photographs of rock and soil material studied in this research.

engineering, 5\# 9\# samples were designed with different ratios of soil and rock to enable study of the influence of the soil-rock ratio. Conditions for these upward infiltration experiments are shown as Table 4.

The preparation method for rock-soil mixture samples was the same as for the traditional calibration method. The processes of standard compaction and probe insertion were carried out in the coaxial tube. The coaxial tube was then bolted to the infiltration base by means of a glass plate and its built-in rubber ring. The upward infiltration experimental process was as described in Section 2.3.1.

\section{Results and Discussion}

4.1. Effect of Different Dry Densities. Figure 5 demonstrates the relationship between water content and the square root of the dielectric constant for samples 1\#, 2\#, and 5\#. Figure 6 compares the water content calculated by the TDR method using the calibration equation form of (2) with the directly 
TABLE 4: Conditions for upward infiltration experiments of rock-soil mixture.

\begin{tabular}{lccccc}
\hline Group & Soil-rock ratio & Pore fluid conductivity $/ \mathrm{mS} \cdot \mathrm{m}^{-1}$ & ${\text { Initial water content } / \mathrm{g} \cdot \mathrm{g}^{-1}}$ & Dry density/g.cm $^{-3}$ & ${\text { Final water content } / \mathrm{g} \cdot \mathrm{g}^{-1}}^{1}$ \\
\hline $1 \#$ & $5: 5$ & 0 & 0.0351 & 1.40 & 0.2099 \\
$2 \#$ & $5: 5$ & 0 & 0.0404 & 1.78 & 0.1376 \\
$3 \#$ & $5: 5$ & 100 & 0.0390 & 1.69 & 0.1213 \\
$4 \#$ & $5: 5$ & 180 & 0.0390 & 1.69 & 0.1330 \\
$5 \#$ & $5: 5$ & 0 & 0.0236 & 1.69 & 0.1485 \\
$6 \#$ & $3: 7$ & 0 & 0.0324 & 1.62 & 0.1781 \\
$7 \#$ & $4: 6$ & 0 & 0.0329 & 1.74 & 0.1241 \\
$8 \#$ & $6: 4$ & 0 & 0.0414 & 1.64 & 0.1344 \\
$9 \#$ & $7: 3$ & 0 & 0.0308 & 1.59 & 0.1242 \\
\hline
\end{tabular}

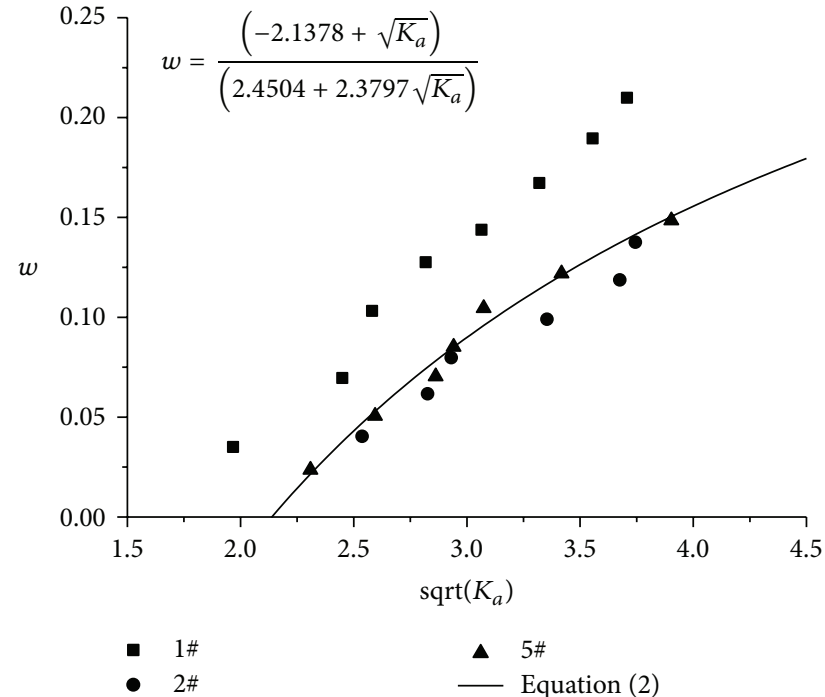

FIGURE 5: Relationship between square root of dielectric constant and gravimetric water content at different dry densities.

measured value. Figure 7 shows the result using the Purdue model. Among the groups, sample $1 \#$ with the dry density of $1.40 \mathrm{~g} / \mathrm{cm}^{3}$ and sample 2\# with $1.78 \mathrm{~g} / \mathrm{cm}^{3}$ correspond to the most loose and compact status of the 5:5 mixture with an initial water content of $0.03 \mathrm{~g} / \mathrm{g}$, respectively. The calibration equation was obtained by fitting the data points of sample $5 \#$ with a dry density of $1.69 \mathrm{~g} / \mathrm{cm}^{3}$.

As shown in Figure 5, the value of dry density has an apparent effect on the relationship between gravimetric water content and dielectric constant. The value of water content calculated by the calibration equation obtained for standard compaction sample will underestimate the result for a rock-soil mixture with lower dry density and overestimate the result for a rock-soil mixture with higher dry density. Taking the calibration curve as the standard, for a given unit sample of rock-soil mixture with a fixed volumetric water content, with increase of dry density, the solid contribution to total dielectric constant increases causing a larger dielectric constant. This leads to the calculated result becoming larger

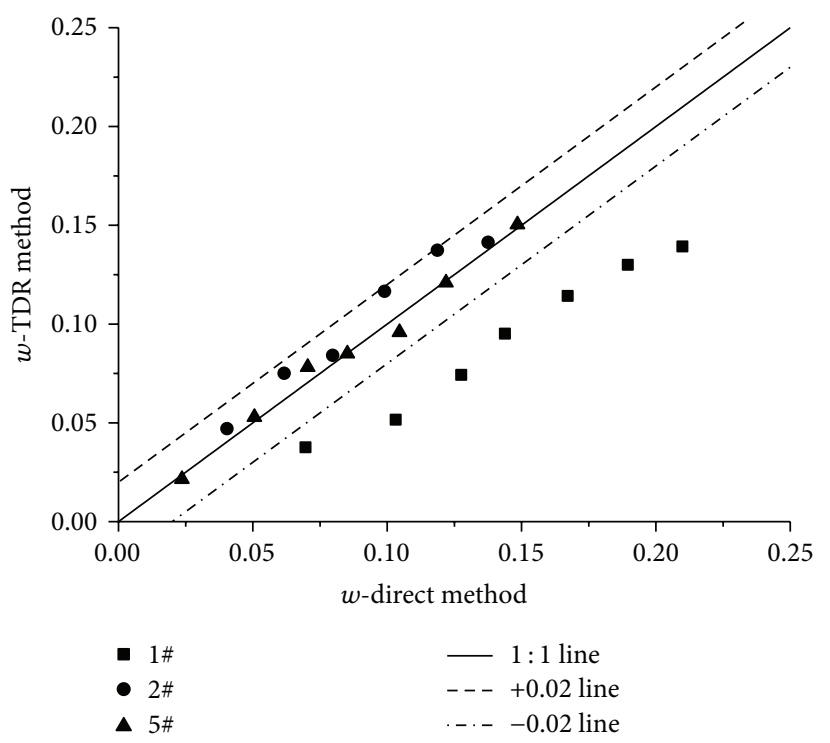

FIGURE 6: Comparison of gravimetric water content by TDR method and directly measured values at different dry densities.

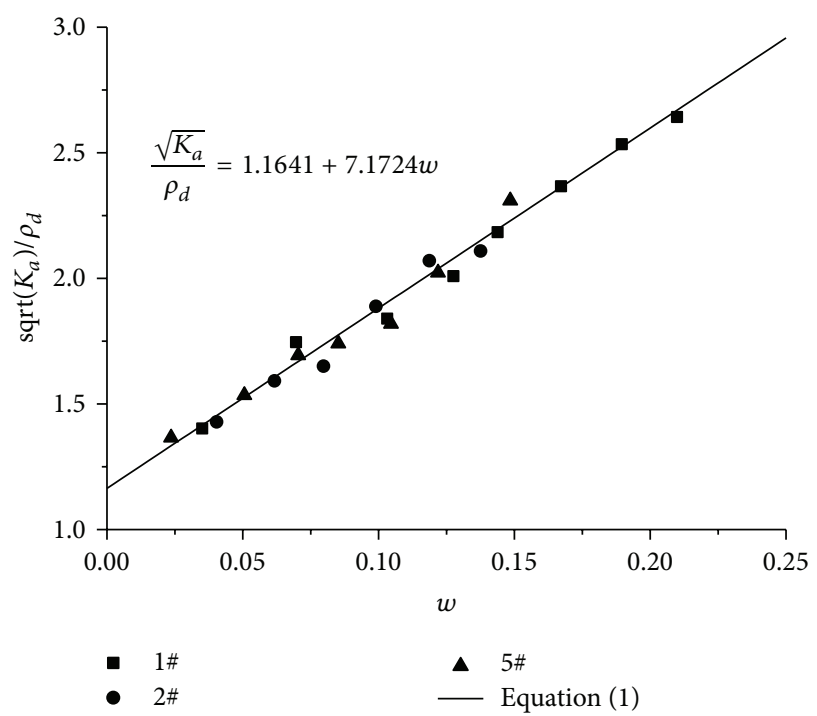

Figure 7: Relationship of Purdue equation at different dry densities. 


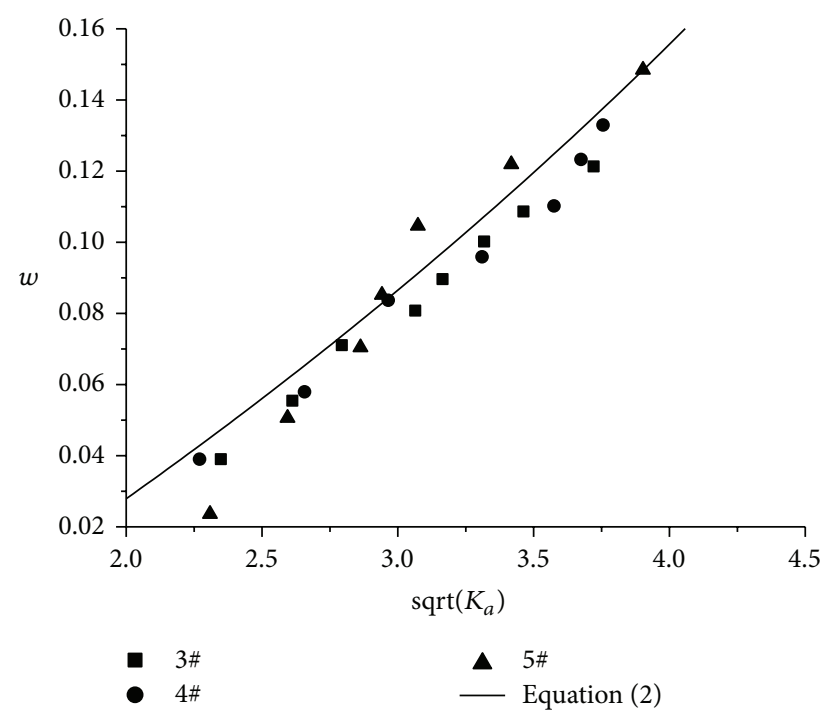

FIGURE 8: Relationship between square root of dielectric constant and gravimetric water content at different pore fluid conductivities.

as the actual value of gravimetric water content decreases. The calibration curve, therefore, overestimates the value of gravimetric water content and vice versa.

As shown in Figure 6, even after calibration, the gravimetric water content result for the loose sample (1\#) is not ideal. The largest errors can be $0.05 \mathrm{~g} / \mathrm{g}$, suggesting that the calibration curve of (2) based on a standard compaction sample has some application limits and not accuracy for samples that have a large difference dry density from calibration sample. The calibration curve, however, has good accuracy when the sample has a dry density close to that of the calibration sample.

As can be seen from Figure 7, when the calibration equation takes account of the influence of dry density, in, for example, the Purdue model, the distribution of data points shows good consistency and the calculated water content errors were within $\pm 0.01 \mathrm{~g} / \mathrm{g}$.

The above discussion makes it clear that the value of dry density has an obvious influence on (2) calculated result and that the effect can be allowed for by using the Purdue model as the calibration curve.

4.2. Effect of Pore Fluid Conductivity. Figure 8 demonstrates the relationship between water content and the square root of the dielectric constant for samples $3 \#, 4 \#$, and 5\#. These have pore fluid conductivities of $100 \mathrm{mS} / \mathrm{m}, 180 \mathrm{mS} / \mathrm{m}$, and $0 \mathrm{mS} / \mathrm{m}$, respectively. Figure 9 compares the water content results when calculated by the TDR method using the calibration equation form of (2) and the directly measured value. The calibration equation was obtained by filling sample 5\# with deionized water as the pore fluid.

As shown in Figure 8, the water content value calculated by the calibration equation obtained using the sample with deionized water as the pore fluid overestimates the result for samples with higher pore fluid conductivities. The increase of pore fluid conductivity causes larger sample energy losses

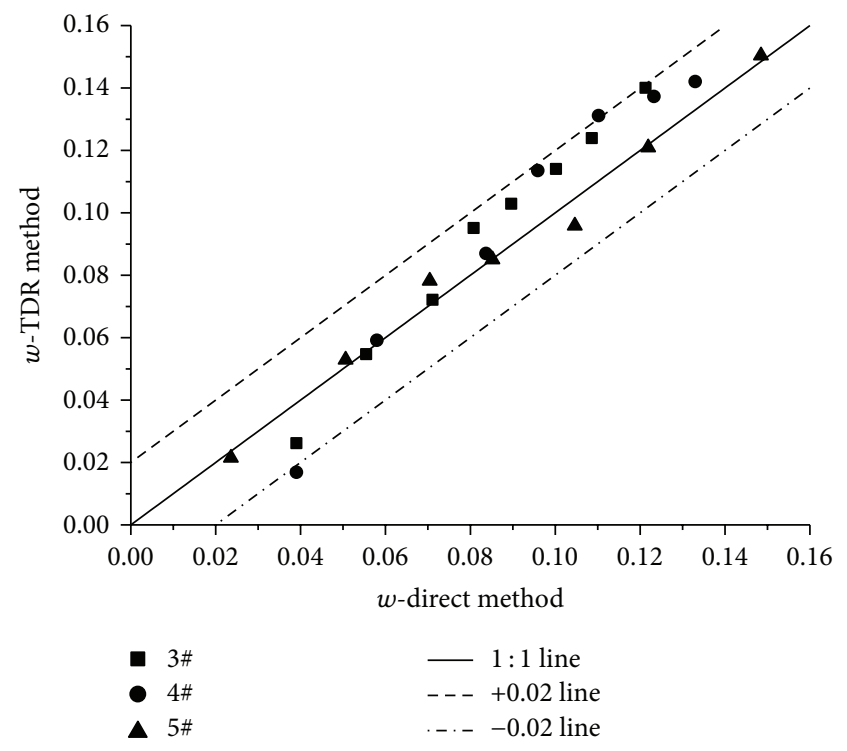

FIGURE 9: Comparison of gravimetric water content by TDR method and direct measured value at different pore fluid conductivities.

under the TDR waveform resulting in a lower dielectric constant, causing the result calculated by the calibration equation to become larger. Comparing the result of $3 \#$ sample with $4 \#$, no major differences are apparent, indicating that the value of pore fluid conductivity is not sensitive to the energy losses and has a limitation. Above that limit, the value of the dielectric constant will not vary. This phenomenon was also discovered for MSW material in studies [20,25]. As can be seen from Figure 9, the water content errors calculated by the calibration equation are within $\pm 0.02 \mathrm{~g} / \mathrm{g}$. Therefore, for the values of pore fluid conductivity encountered in geotechnical engineering, the influence of pore fluid conductivity can be ignored.

4.3. Result of Soil-Rock Ratio. The influence of the soilrock ratio on the relationship between water content and dielectric constant can be attributed to the different dielectric contribution of the various solids and the different structures and compactness of the sample compacted with the same compaction energy levels. To eliminate the effect of dry density, Figure 10 presents the Purdue model results for samples 5\# 9\#.

As can be seen from Figure 10, for a mixture with the same type of rock and soil material components, the data points show good coherence for mixtures with different soilrock ratios. The calibration equation is not sensitive to the soil/rock ratio.

In order to quantify and evaluate the influence of the soil-rock ratio on the calculated water content, a regression analysis was conducted for the data points of sample 5\#. The calibration curve was obtained as

$$
\frac{\sqrt{K_{a}}}{\rho_{d}}=1.1641+7.1724 w
$$


TABLE 5: Errors for water content of different soil-rock ratio.

\begin{tabular}{lccccc}
\hline Group & $6 \#$ & $7 \#$ & $5 \#$ & $8 \#$ & $9 \#$ \\
\hline Equation (1) & & & & & \\
$\quad$ Max & 0.0088 & 0.0172 & 0.0133 & 0.0089 & 0.0305 \\
E & 0.0056 & 0.0089 & 0.0058 & 0.0057 & 0.0142 \\
SEE & 0.0077 & 0.0112 & 0.0085 & 0.0076 & 0.0194 \\
\hline
\end{tabular}

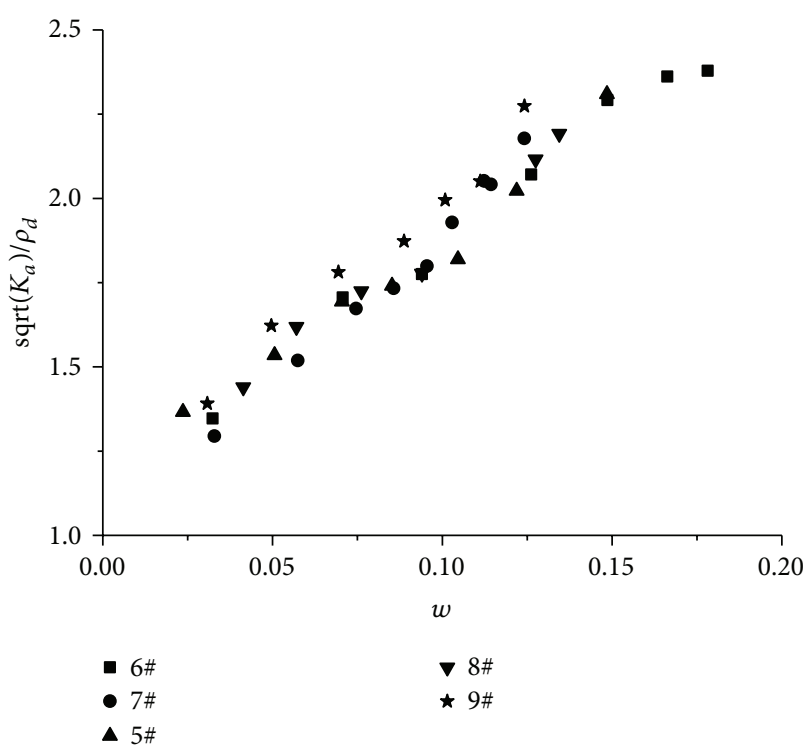

FIgURE 10: Relationship using the Purdue equation.

From (7), the error statistics for the calibration curve calculated water content applied to samples $5 \# \sim 9 \#$ is shown in Table 5, where "Max" represents the largest error between (7) calculated water contents and the directly measured value.

As shown in Table 5, with increase of soil-rock ratio, the values of $E$ and SEE for each group do not contain any trends. When (1) is adopted as the calibration equation, the maximum error is within $\pm 0.03 \mathrm{~g} / \mathrm{g}$ and all the statistical errors are low, suggesting that the calibration curve is accurate for all data points. The errors caused by material differences can be ignored if the calibration model has taken into account the effect of dry density.

As discussed above, the research result shows that the dielectric constant value for a rock-soil mixture is mainly determined by the water content and dry density. The influences of pore fluid conductivity and soil-rock ratio are relatively small.

4.4. Unified Empirical Equations for Geomaterials. In order to compare the calibration results for typical soils, Figure 11 presents in Section 2 of this paper the relationship between the water content and the square root of the dielectric constant for rock-soil mixtures of different soil-rock ratios (5\# 9\#) including the three typical soils.

As shown in Figure 11, the data points for the rock-soil mixture are mainly located below the curve for soils at low water contents. This is because, at this condition, the dry

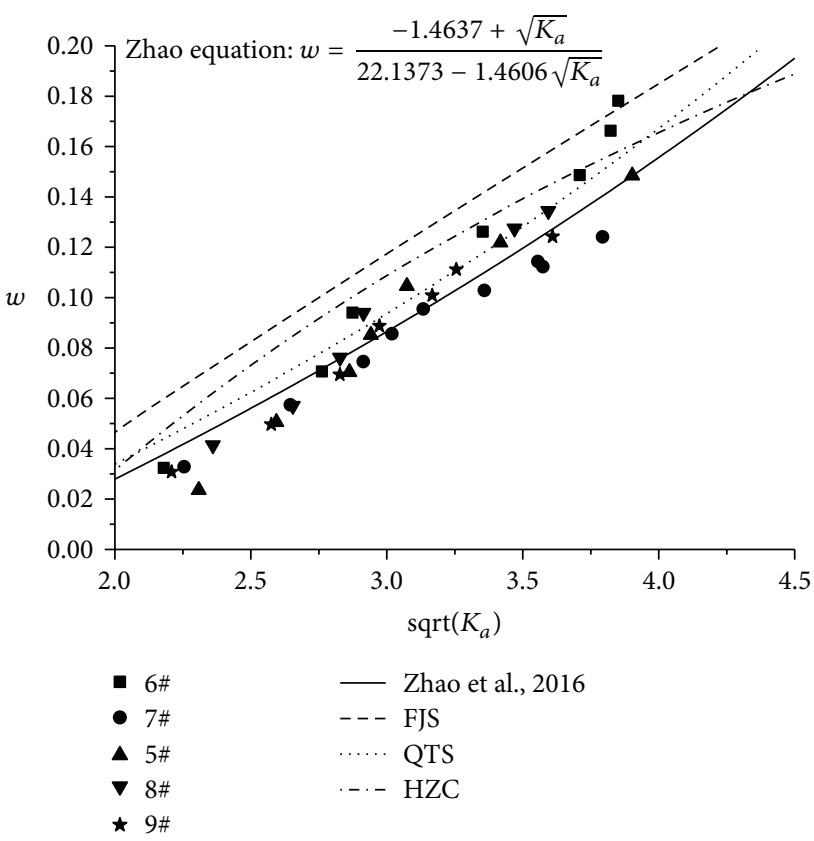

FIGURE 11: Relationship between the square root of the dielectric constant and gravimetric water content.

density is the major factor influencing the value of dielectric constant except for the water content. After being compacted, a rock-soil mixture usually has a higher dry density. The contribution of the solid phase to the dielectric constant is more than that for soils with the same volumetric water content, hence, leading to a larger dielectric constant. The rock-soil mixture data points, therefore, are located below soil equations curve. With an increase of water content, the difference is clearly reduced and the water content of the sample becomes the element determining the value of the dielectric constant. The empirical calibration equation for soil materials proposed by Zhao et al. [10] is also shown in Figure 11. As seen in Figure 11, the empirical Zhao equation shows good accordance with the rock-soil mixture results. This is mainly because Zhao's equation was obtained through fitting the experimental data points for soils the dry densities of which are within $1.1 \sim 2.3 \mathrm{~g} / \mathrm{cm}^{3}$.

Since the field test environment is complex, it is difficult to conduct calibration tests. If errors can be accepted, unified empirical calibration equations can be applied to estimate the water content preliminarily in the field TDR test. For geomaterials, three empirical equations are recommended to test for water content without calibration as follows:

$$
\begin{aligned}
& w=\frac{\left(-1.4637+\sqrt{K_{a}}\right)}{\left(22.1373-1.4606 \sqrt{K_{a}}\right)}, \\
& \frac{\sqrt{K_{a}}}{\rho_{d}}=0.9786+9.1839 w,
\end{aligned}
$$

$w$

$$
=\frac{\left(0.3039 \rho_{d} / \rho_{w}-2.1851\right)+\sqrt{K_{a}}}{\left(18.0283 \rho_{d} / \rho_{w}-17.9531\right)+\left(-0.6806 \rho_{d} / \rho_{w}+1.8351\right) \sqrt{K_{a}}},
$$




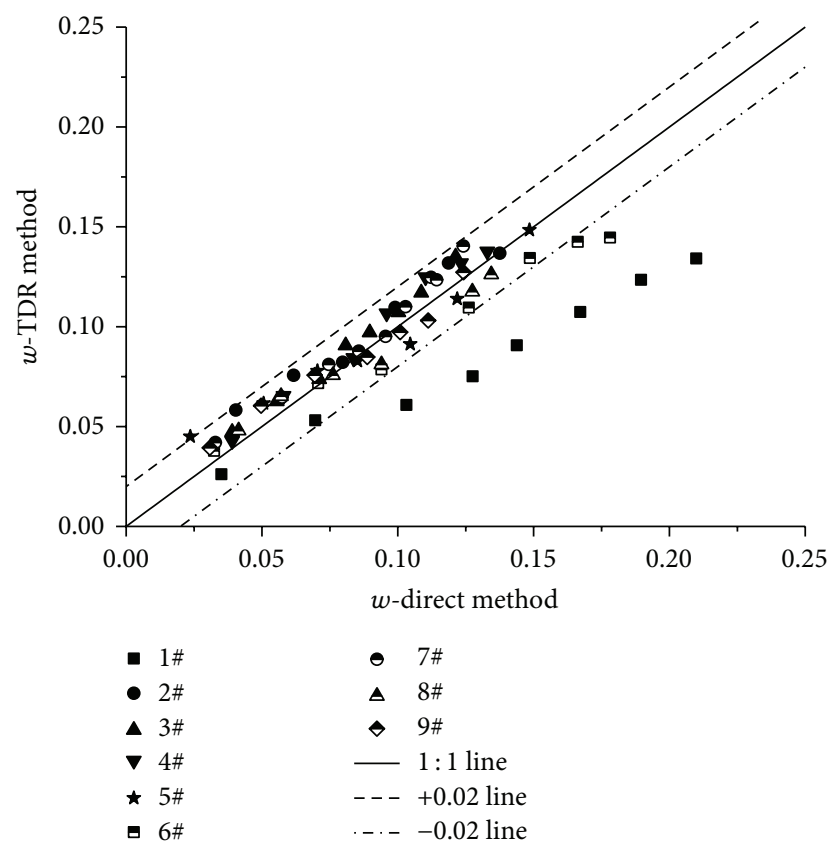

FIGURE 12: Comparison of gravimetric water content by (8) of TDR method and directly measured values.

where (8) and (10) were directly adopted as Zhao's initial equations. The empirical constants were obtained by regression analysis applied to the collected data points. There were 45 types of soil samples in total and 352 experimental points.

Figure 12 compares water content results calculated by the TDR method using the calibration equation form of (8) with the directly measured values for all rock-soil mixtures studied in this research.

As can be seen from Figure 12, the major data point errors are within $\pm 0.02 \mathrm{~g} / \mathrm{g}$ except for sample $1 \#$ with its looser condition, suggesting that (8) is accurate for rock-soil mixtures. For some engineering inspections such as utilizing the TDR penetrometer for continuous tests at different depths, information on the dry density is usually not available. In such cases, (8) can then be adopted to conveniently test the water content.

When the value of dry density is known, (9) and (10) can be used to calculate the water content. Figure 13 demonstrates the water contents calculated by (10). As shown in Figure 13, the distribution of data points shows consistent and not much scatter and the calculated water content errors are within $\pm 0.01 \mathrm{~g} / \mathrm{g}$. Therefore, when the influence of dry density is considered, the errors due to material differences can be ignored. Equation (10), therefore, has good accuracy for estimating the water content value. The calculated result using (9) is similar but is not given here due to paper length limits.

\section{Conclusions}

This study investigated a TDR calibration apparatus that proved suitable for use with compacted rock and soil mixture samples if an infiltration device is installed at the bottom

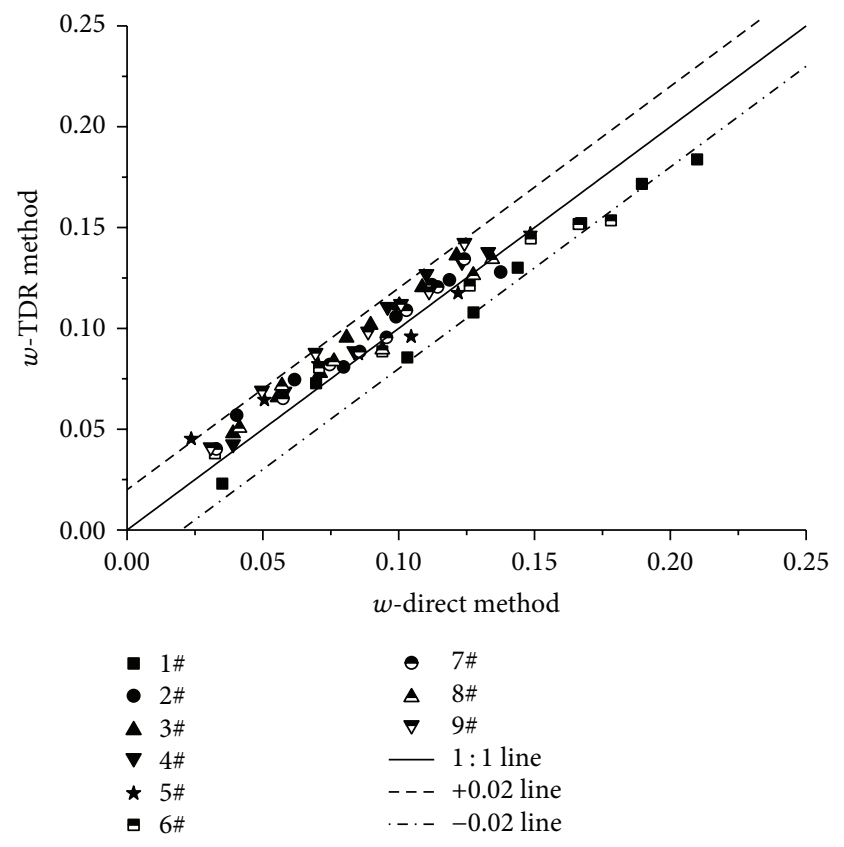

FIGURE 13: Comparison of gravimetric water content by (10) of TDR method and directly measured values.

of the TDR coaxial test tube. The influence of dry density, pore fluid conductivity, and soil-rock ratio on the relationship between gravimetric water content and dielectric constant has been studied. The conclusions are as follows:

(1) The calibration apparatus enabling the use of the TDR coaxial test tube with upward infiltration can solve the problems of probe insertion and be applied to conveniently and efficiently test the relationship between the gravimetric water content and the dielectric constant of compacted geomaterials.

(2) The value of the dielectric constant for rock-soil mixture is mainly determined by the water content and dry density. When the calibration equation obtained using the standard compaction sample does not allow for the effect of dry density, the value of water content calculated will underestimate the true value for a rock-soil mixture with lower dry density and overestimate the value for rock-soil mixtures with higher dry density. The errors will be excessive when the dry density of a field sample is very different from that of the calibration sample. Better results are obtained using calibration models which do take account of the influence of dry density.

(3) For the values of pore fluid conductivity typically encountered in geotechnical engineering, the influence of pore fluid conductivity can be ignored. Likewise, when dry density is considered, the influence of material variance due to the soil-rock ratio is also relatively small and can be ignored.

(4) Zhao's equations prove to be accurate for rock-soil mixtures and can be conveniently and efficiently 
utilized in the field to test water content without calibration.

\section{Competing Interests}

The authors declare that they have no competing interests.

\section{Acknowledgments}

The authors acknowledge the support of a research grant from the National Basic Research Program of China (973 Program) (no. 2014CB047005).

\section{References}

[1] V. P. Drnevich, C. P. Lin, Q. Yi et al., "Real-time determination of soil type, water content, and density using electromagnetics," Joint Transportation Research Program 177, 2001.

[2] G. C. Topp, J. L. Davis, and A. P. Annan, "Electromagnetic determination of soil water content: measurements in coaxial transmission lines," Water Resources Research, vol. 16, no. 3, pp. 574-582, 1980.

[3] W. N. Herkelrath, S. P. Hamburg, and F. Murphy, "Automatic, real-time monitoring of soil moisture in a remote field area with time domain reflectometry," Water Resources Research, vol. 27, no. 5, pp. 857-864, 1991.

[4] M. van Praagh, M. Persson, and K. M. Persson, "Assessment of hydrological parameters in pre-treated waste by time-domain reflectometry," in Proceedings of the 11th International Waste Management and Landfill Symposium (Sardinia '07), CISA Publisher, Cagliari, Italy, October 2007.

[5] C. Yu, A. W. Warrick, M. H. Conklin, M. H. Young, and M. Zreda, "Two- and three-parameter calibrations of time domain reflectometry for soil moisture measurement," Water Resources Research, vol. 33, no. 10, pp. 2417-2421, 1997.

[6] K. Masbruch and T. P. A. Ferré, "A time domain transmission method for determining the dependence of the dielectric permittivity on volumetric water content: an application to municipal landfills," Vadose Zone Journal, vol. 2, no. 2, pp. 186192, 2003.

[7] S. I. Siddiqui and V. P. Drnevich, A New Method of Measuring Density and Moisture Content of Soil Using the Technique of Time Domain Reflectometry, Joint Highway Research Project, Purdue University, 1995.

[8] X. Yu and V. P. Drnevich, "Soil water content and dry density by time domain reflectometry," Journal of Geotechnical and Geoenvironmental Engineering, vol. 130, no. 9, pp. 922-934, 2004.

[9] S. Jung, New methodology for soil characterization using time domain reflectometry (TDR) [Ph.D. thesis], Purdue University, 2011.

[10] Y. Zhao, D. S. Ling, Y. L. Wang, B. Huang, and H. Wang, "Study on a calibration equation for soil water content in field tests using time domain reflectometry," Journal of Zhejiang University-SCIENCE A, vol. 17, no. 3, pp. 240-252, 2016.

[11] H. L. Wang, F. Xu, R. P. Chen et al., "Research on water content measurement of coarse-grained particles using TDR technology," Journal of China Three Gorges University (Natural Sciences), vol. 36, no. 6, pp. 37-42, 2014.
[12] R. P. Chen, J. Wu, S. Qi, and H.-L. Wang, "A method for measuring hydraulic parameters of coarse-grained soils of highspeed railway subgrade," Rock and Soil Mechanics, vol. 36, no. 12, pp. 3365-3372, 2015.

[13] Y.-J. Cui, T. V. Duong, A. M. Tang, J.-C. Dupla, N. Calon, and A. Robinet, "Investigation of the hydro-mechanical behaviour of fouled ballast," Journal of Zhejiang University: Science A, vol. 14, no. 4, pp. 244-255, 2013.

[14] G. C. Topp, J. L. Davis, and A. P. Annan, "Electromagnetic determination of soil water content using TDR: I. Applications to wetting fronts and steep gradients," Soil Science Society of America Journal, vol. 46, no. 4, pp. 672-678, 1982.

[15] A. Nadler, S. Dasberg, and I. Lapid, “Time domain reflectometry measurements of water content and electrical conductivity of layered soil columns," Soil Science Society of America Journal, vol. 55, no. 4, pp. 938-943, 1991.

[16] P. A. Ferré, D. L. Rudolph, and R. G. Kachanoski, "Spatial averaging of water content by time domain reflectometry: implications for twin rod probes with and without dielectric coatings," Water Resources Research, vol. 32, no. 2, pp. 271-279, 1996.

[17] M. H. Young, J. B. Fleming, P. J. Wierenga, and A. W. Warrick, "Rapid laboratory calibration of time domain reflectometry using upward infiltration," Soil Science Society of America Journal, vol. 61, no. 3, pp. 707-712, 1997.

[18] Y.-M. Chen, "A fundamental theory of environmental geotechnics and its application," Chinese Journal of Geotechnical Engineering, vol. 36, no. 1, pp. 1-46, 2014.

[19] R. P. Chen, Y. Chen, W. Chen, and Y. Chen, “Time domain reflectometry for water content measurement of municipal solid waste," Environmental Engineering Science, vol. 29, no. 6, pp. 486-493, 2012.

[20] Y. Gong, Q. Cao, and Z. Sun, "The effects of soil bulk density, clay content and temperature on soil water content measurement using time-domain reflectometry," Hydrological Processes, vol. 17, no. 18, pp. 3601-6314, 2003.

[21] M. J. Staub, J.-P. Laurent, J.-P. Gourc, and C. Morra, "Applicability of time domain reflectometry water content measurements in municipal solid waste," Vadose Zone Journal, vol. 9, no. 1, pp. 160-171, 2010.

[22] J. M. Baker and R. R. Allmaras, "System for automating and multiplexing soil moisture measurement by time-domain reflectometry," Soil Science Society of America Journal, vol. 54, no. 1, pp. 1-6, 1990.

[23] ASTM D 698-12, "Standard test method for water content and density of soil in place by Time Domain Reflectometry (TDR)," Annual Book of ASTM Standards, ASTM, West Conshohocken, $\mathrm{Pa}, \mathrm{USA}, 2012$.

[24] ASTM, "Standard practice for classification of soils for engineering purposes (Unified Soil Classification System)," Annual Book of ASTM Standards D 2487-11, ASTM International, West Conshohocken, Pa, USA, 2011.

[25] R. S. Li and C. Zeiss, "In situ moisture content measurement in MSW landfills with TDR," Environmental Engineering Science, vol. 18, no. 1, pp. 53-66, 2001. 


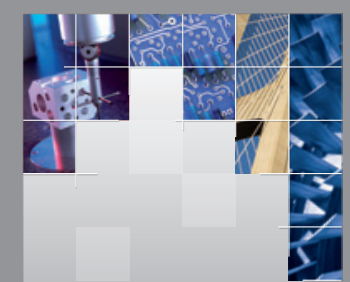

\section{Enfincering}
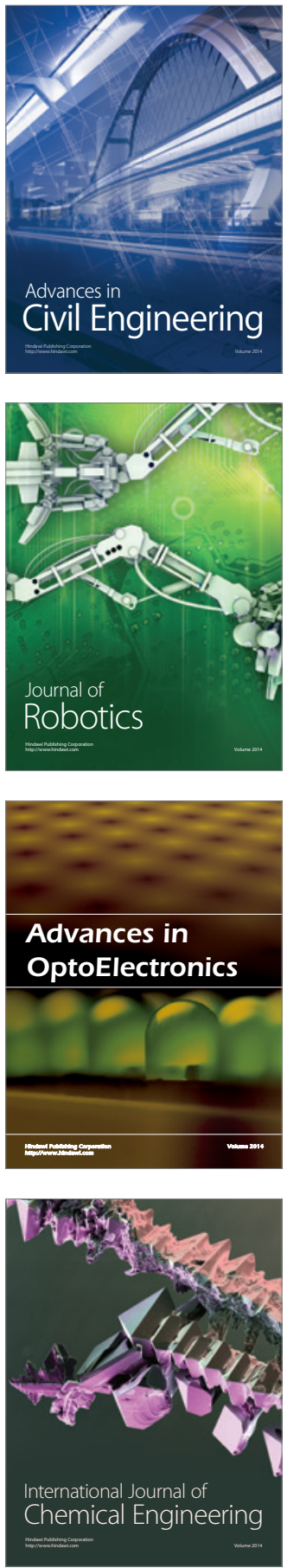

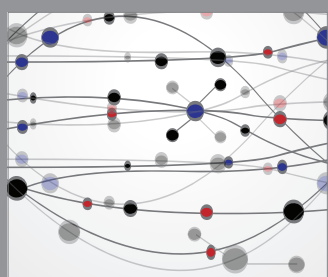

The Scientific World Journal

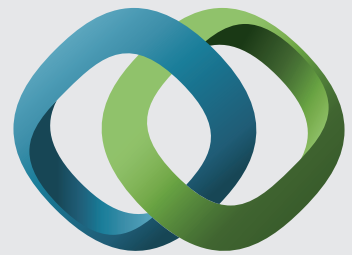

\section{Hindawi}

Submit your manuscripts at

http://www.hindawi.com
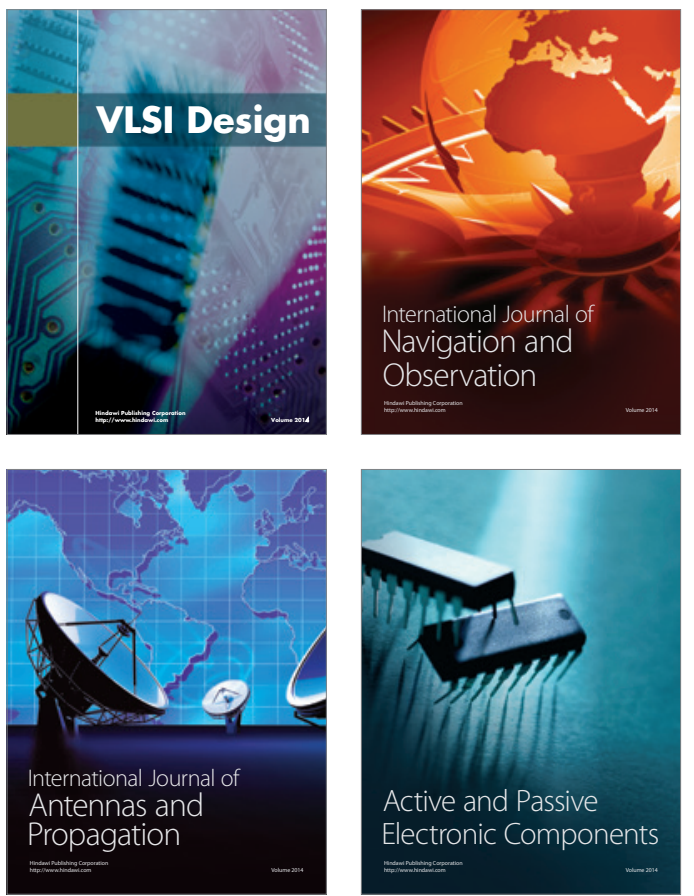
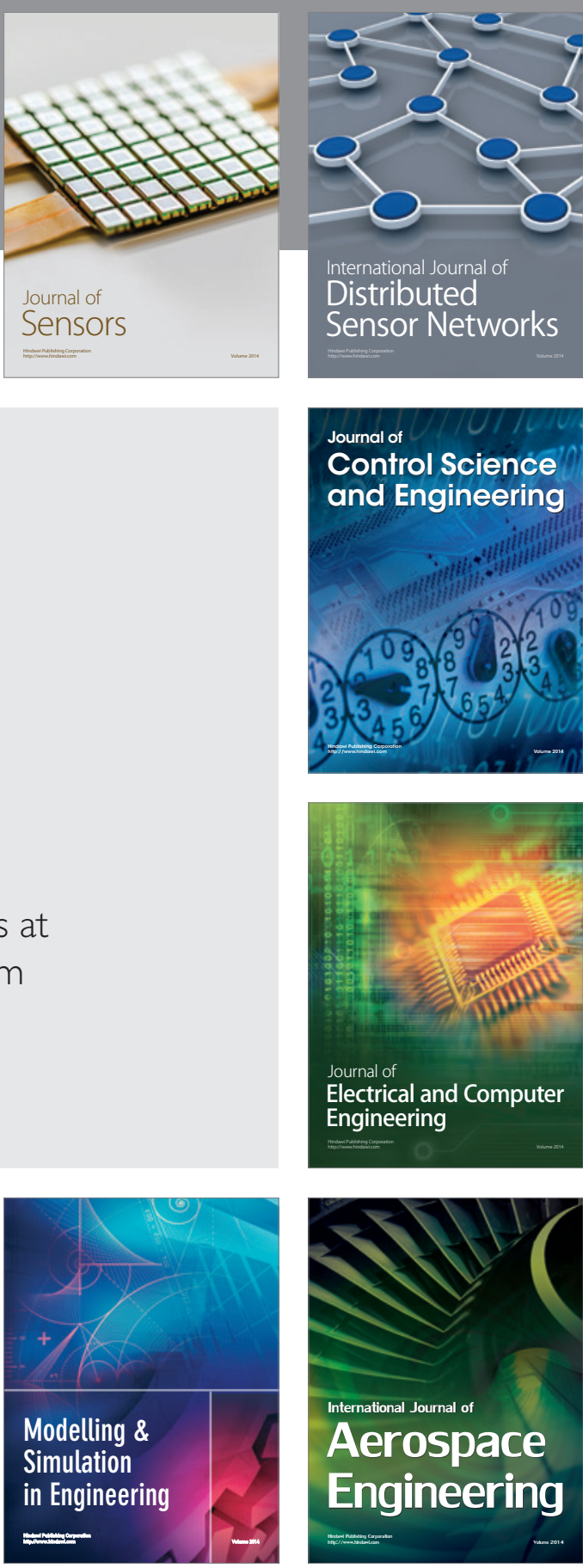

International Journal of

Distributed

Sensor Networks

Journal of

Control Science

and Engineering
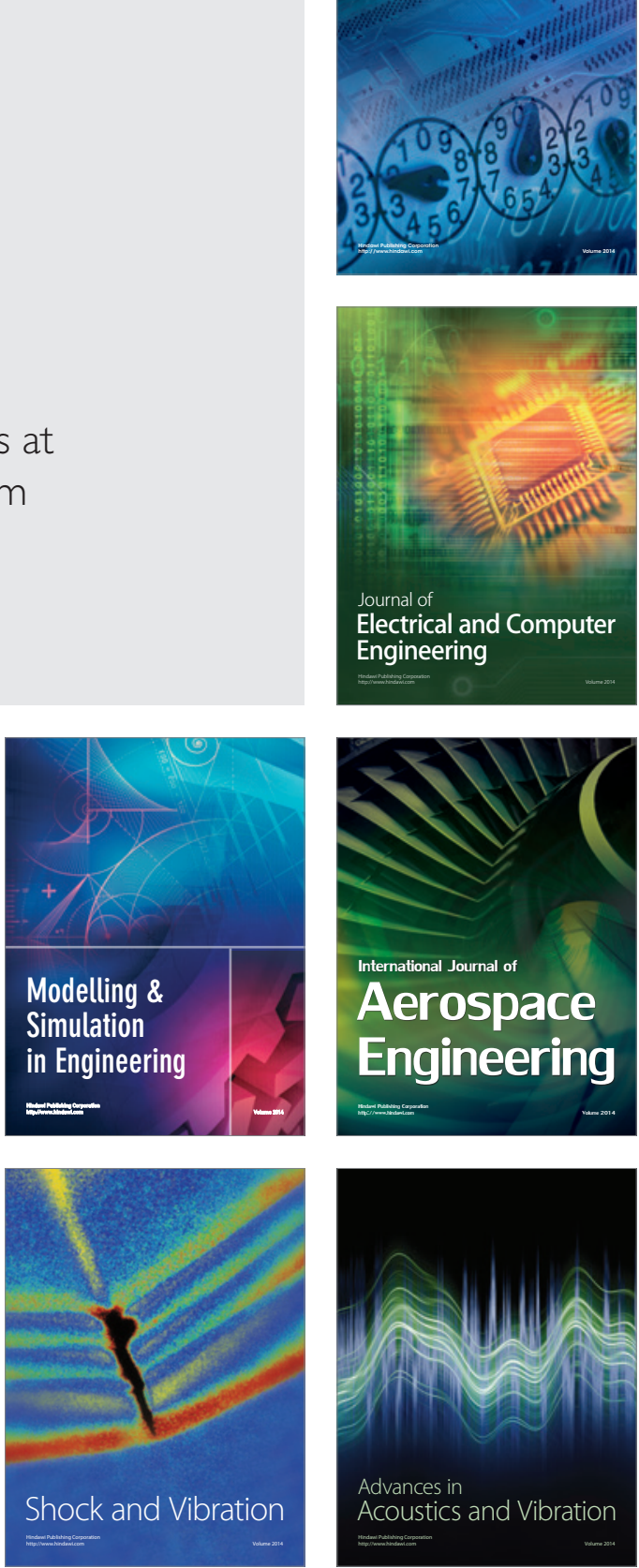